$\stackrel{W}{=}$

Global journals Inc.

औf

\title{
Psychometric Properties of DASS-21and Predictive Model of Negative Affectivities in Individuals with Different Pain Conditions
}

By Juliana Alvares Duarte Bonini Campos, Fernanda Salloume Sampaio Bonafé, Bianca Gonzalez Martins, Lucas Arrais Campos \& João Maroco

Abstract- The aims of this cross-sectional study were i) to evaluate the psychometric properties of the Depression Anxiety and Stress Scale (DASS-21) in adults with different temporal conditions of pain; ii) to compare the Depression, Anxiety and Stress subscale scores in different individuals; iii) to estimate the prevalence of negative affectivity; and iv) to elaborate a predictive model considering aspects related to the development of negative affectivity. A total of 1,150 individuals (mean age: $38.6, \mathrm{SD}=10.8$ years; $78.9 \%$ women) participated. The fit of the model of DASS-21 to the data was estimated by confirmatory strategy. The Depression, Anxiety and Stress mean scores of participants with different temporal conditions of pain were compared. The association between Depression, Anxiety and Stress and the presence or absence of pain was assessed by the chi-square test and odds ratio (OR). A multiple logistic regression model was developed to estimate the probability of negative affectivity in the sample.

GJMR-K Classification: NLMC Code: WF 330

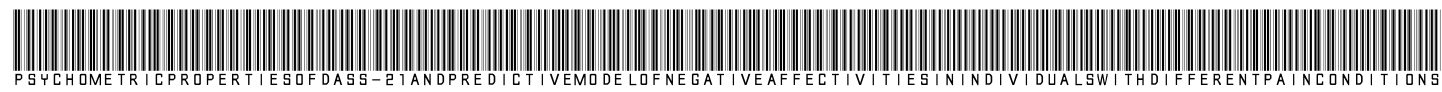

Strictly as per the compliance and regulations of:

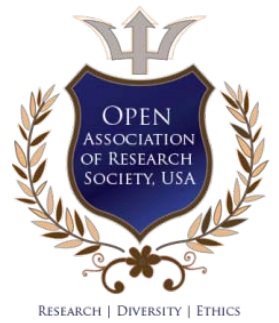

(c) 2020. Juliana Alvares Duarte Bonini Campos, Fernanda Salloume Sampaio Bonafé, Bianca Gonzalez Martins, Lucas Arrais Campos \& João Maroco. This is a research/review paper, distributed under the terms of the Creative Commons AttributionNoncommercial 3.0 Unported License http://creativecommons.org/licenses/by-nc/3.0/), permitting all non-commercial use, distribution, and reproduction in any medium, provided the original work is properly cited. 


\title{
Psychometric Properties of DASS-21and Predictive Model of Negative Affectivities in Individuals with Different Pain Conditions
}

\author{
Negative Affectivity in Pain \\ Juliana Alvares Duarte Bonini Campos ${ }^{\alpha}$, Fernanda Salloume Sampaio Bonafé ${ }^{\sigma}$, \\ Bianca Gonzalez Martins ${ }^{\circ}$, Lucas Arrais Campos ${ }^{\omega}$ \& João Maroco ${ }^{*}$
}

Abstract- The aims of this cross-sectional study were i) to evaluate the psychometric properties of the Depression Anxiety and Stress Scale (DASS-21) in adults with different temporal conditions of pain; ii) to compare the Depression, Anxiety and Stress subscale scores in different individuals; iii) to estimate the prevalence of negative affectivity; and iv) to elaborate a predictive model considering aspects related to the development of negative affectivity. A total of 1,150 individuals (mean age: $38.6, \mathrm{SD}=10.8$ years; $78.9 \%$ women) participated. The fit of the model of DASS-21 to the data was estimated by confirmatory strategy. The Depression, Anxiety and Stress mean scores of participants with different temporal conditions of pain were compared. The association between Depression, Anxiety and Stress and the presence or absence of pain was assessed by the chi-square test and odds ratio (OR). A multiple logistic regression model was developed to estimate the probability of negative affectivity in the sample. The model of DASS-21 presented adequate fit to the data $\left(X^{2} / d f=6.24 ; \mathrm{CFI}=0.98 ; \mathrm{TLI}=0.98 ; \mathrm{RMSEA}=0.067\right)$. Convergent validity (AVE $=0.57-0.74$ ) and reliability ( $\alpha$ and CR $=0.90-0.95$ ) were also adequate. The mean scores of negative affectivity were higher among individuals with pain regardless of pain type $\left(F_{\text {Welch }}=14.92-19.11 ; p<0.001\right)$. Having pain increased the risk of negative affectivity $(\mathrm{OR}=$ 2.43-2.90). Having religion was a protective factor for the occurrence of Depression (OR $=0.57$ ) and Anxiety $(\mathrm{OR}=0.60)$. The presence of chronic disease, pain, insomnia, and high economic level were risk factors for Depression (OR $=1.50-2.46)$ and Anxiety (OR $=1.71-3.95)$. For the occurrence of Stress, only the presence of pain and insomnia were significant risk factors (OR $=1.96-2.70)$. In conclusion, individual characteristics and pain are relevant factors for experiencing negative affectivity and should be considered in studies and clinical management.

Author a p: Department of Food Science and Nutrition, São Paulo State University (Unesp), School of Pharmaceutical Sciences, Araraquara, Brazil.

Author $\sigma$ w: Dental Science Program, São Paulo State University (Unesp), School of Dentistry, Araraquara, Brazil.

Author ¥: William James Center for Research (WJCR), University Institute of Psychological, Social, and Life Sciences (ISPA), Lisbon, Portugal. e-mail: jpmaroco@ispa.pt

\section{INTRODUCTION}

N egative affectivity is a tendency of a person to experience negative emotions [1], which may manifest as a state or trait, i.e., be temporary with varying intensities over time or a personal disposition. This is a complex construct that includes negative emotions such as, for example, stress, anxiety, and depression. Research on stress, anxiety, and depression has received significant attention because of the increased prevalence of these conditions and their impact on people's lives.

Although some overlap exist, stress, anxiety, and depression are distinct conditions. According to Lovibond and Lovibond [2], stress is defined as a persistent state of over-excitement that reflects as a constant difficulty in meeting and coping with everyday difficulties and challenges. Anxiety involves the anticipation of negative events that normally, but not exclusively, are of a psychological nature. Still, anxiety is an adaptive state or a psychological disorder and what determines the difference between these occurrences is the severity of this condition and the duration of this state [3]. Depression, in turn, is a psychopathology with complex etiology that involves several symptoms such as feelings of distress, hopelessness, devaluation of life, self-deprecation, disinterest, reduced motivation, and inertia. Stress and anxiety can have positive valence when they occur as an adaptive/physiological reaction or negative valence when they trigger psychological disorders as a result of ineffective coping strategies $[4,5]$.

The measurement of stress, anxiety, and depression is a challenge for which several instruments have been proposed. The Depression, Anxiety and Stress Scale (DASS) is an interesting screening tool because it simultaneously evaluates the three negative affectivity conditions and can be used in both clinical and research contexts [2]. The theoretical construction of this instrument was based on the tripartite model of anxiety and depression proposed by Clark and Watson [6], which seeks the maximum differentiation between 
the two conditions by separating specific characteristics and grouping shared symptoms. The Tripartite Model of Anxiety and Depression helps explain the comorbidity between anxious and depressive symptoms and disorders. This model divides the symptoms of anxiety and depression which helps explain common and distinct aspects of depression and anxiety. The tripartite model consists of general distress, physiological hyperarousal (specific anxiety), and anhedonia (specific depression), and a model with diagnosis of mixed anxiety-depression was proposed. The DASS allows the assessment of anxiety and depression prevalence and the risk of their occurrence. Thus, it can be used to identify these conditions in a population as well as develop preventive and curative measures.

Events and characteristics associated with negative affectivity include pain and chronic illness, insomnia, and individual characteristics (such as sex, age, religion / spirituality, work activity and economic level). Pain is a stressful condition that can trigger a cascade of psychophysiological processes and elicit emotional reactions. Pain-related anxiety and depression have often been reported in patients with chronic pain and may contribute to negative outcomes of pain conditions such as overestimation of pain intensity, lower chance of symptom regression, greater functional impairment in physical and social aspects [79]. Likewise, individuals with chronic diseases may also present concomitant depression and anxiety, since chronic diseases may limit the person's actions and engagement in gratifying activities [10], favoring his or her isolation [11]. However, the evaluation of negative affectivities in individuals without chronic pain condition is still scarce. Thus, studies that investigate the influence of different pain conditions on these affectivities may be relevant for clinical management.

With regard to insomnia, this can be defined as difficulty in initiating or maintaining sleep [12]. Studies report evidence of a bidirectional relationship between insomnia and anxiety and depression, i.e., insomnia may be the cause or consequence of these emotional states [12, 13]. Thus, the evaluation of insomnia in the context of depression and anxiety is important, since it can negatively influence a person's life; insomnia could be used as a marker for anxiety and depression [12].

Regarding demographic characteristics, the literature has pointed out that different characteristics influence the occurrence of negative affectivities. However, some seem to be more commonly addressed as gender, religion and economic level of individuals. Sex has a significant impact in depression, anxiety, and stress, with women having, in general, higher scores than men [14, 15]. According to lqbal et al. [14], this is due in part to women expressing their emotions more easily than men. For some authors [16-18] this fact refers to the socio-cultural repertoire that influences the interpretation of the perception of emotional representations that are often supported by sexual stereotypes where men are attributed strength and endurance and women emotion and affection. Thus, Fernández and Vergara [19] emphasize that the greatest expression of women's emotional experience is related to socio-cultural and interpersonal behaviors that, in turn, reinforce the ideologies and justifications for existence of different behaviors manifested by men and women.

In addition, studies have reported an inverse relationship between age and negative affectivity, with younger individuals experiencing more negative emotions, which decline with advancing age $[20,21]$. Although older people are more prone to present compromised health and persistent pain conditions, according to Wood et al. [22], their lower negative affectivity may be related to less exposure to workrelated stressors and dealing with pain differently from younger individuals, generally accepting painful conditions as a part of the aging process. Another aspect is that younger people usually have a smaller set of coping strategies than older people [23].

The reported association between religion/spirituality and negative affectivity [24-26] is based on religious people having positive coping strategies for difficult experiences, as they undergo psychological adaptations more easily, increasing their resilience and reducing feelings of depression, anxiety, and stress. Thus, religion can act as a protective factor for negative affectivity [26].

The role of social factors, such as work activity and economic level, in negative affectivities have also been highlighted [22, 27-29]. Work activities have been seen as a dual factor [28]: positive, for being the source of subsistence, and negative, for often being a source of stress that can affect mental health [22]. These approaches reflect the psychosocial conception of work, in which affectivity, the social role of work, and the physical aspects of the activity are considered together [28]. The difficulty in dealing emotionally with workrelated stressors may favor negative feelings and trigger disabling illnesses, including mental health problems. In addition, some studies indicate an inverse association between the economic level and depression and stress [29-31]. According to Adler et al. [29], a high purchasing power reduces the risk of facing economic problems, which can reduce the risk of negative affectivity.

Thus, studies that seek to identify aspects related to stress, anxiety, and depression in samples with different characteristics (e.g. different pain conditions) are relevant for providing evidence that can be accounted for and incorporated into clinical practice. These studies may lead to a more integrated, individualized, and decisive evaluation of emotional conditions, preventing or maintaining patients' mental health. 
This study was carried out with the objective of i) evaluating the psychometric properties of the Depression, Anxiety and Stress Scale (DASS-21) in adults with different pain types (no pain, acute pain, chronic recurring pain, and chronic continuous pain), ii) comparing the scores of depression, anxiety, and stress among groups, iii) estimating the prevalence of negative affectivity, and iv) elaborating a predictive model taking into account aspects relevant to the occurrence of depression, anxiety, and stress in the sample.

\section{il. Methods}

\section{a) Study design and sampling}

The study presented a cross-sectional design with a non-probabilistic sampling (for convenience). Adults (age $\geq 18$ ) seeking dental care at clinics (Radiology, Periodontics, Restorative Dentistry, Emergency, Endodontics, Prosthetics, Temporomandibular Dysfunction, Oral Medicine, and Surgery) of the School of Dentistry of Araraquara, from 2015 to 2016, were invited to participate. The establishment of the target population (dental patients) was based on the fact that it was composed of individuals with different painful conditions and without pain, which was necessary to compose the subsamples of the present study. The option of working with dental patients was based on the researchers' access to the clinics of the School of Dentistry of Araraquara. Only individuals aged 18 or over and who agreed to participating in the study were included; individuals who sought care at the special patients' clinics were excluded.

The minimum sample size was estimated using the proposal by Kim [32], which considers the degrees of freedom of the model (df), the significance level $(\alpha)$ and the power analysis. Considering that DASS-21 presents $\mathrm{df}=186$ and using $\alpha=5 \%$ and power $=80 \%$, the minimum sample size estimated was 116 subjects. To calculate the sample size, we used the software IBM SPSS Statistics 22 (IBM Corp., Armonk, N.Y., USA).

Because the study establishes a sample of individuals with four different pain conditions (no pain, acute pain, chronic recurring pain, and chronic continuous pain), the minimum sample size was considered for each one of these groups.

\section{b) Measuring instrument}

Participants were classified into groups according to the pain condition. It should be clarified that, although the participants were dental patients, pain investigation was performed considering any painful event not limited to dental issues (dental pain $=37.4 \%$; headache $=16.7 \%$; orofacial musculoskeletal $=1.6 \%$; bodily musculoskeletal $=37.2 \%$; bodily other pain $=$ $7.1 \%)$. For this, the proposal from the International Association for the Study of Pain (IASP) was considered $[33,34]$. Individuals were first asked about the presence or lack of pain in the last 24 hours. Those who reported no pain in the prior 24 hours were included in the "no pain" group. Individuals who reported pain were also asked regarding the time of pain onset. If the pain onset occurred less than 3 months ago, the individual was included in the "acute pain" group. If the individuals reported pain onset equal to or greater than 3 months, they were asked about the temporal pattern of pain (crises/episodes or continuous). Those who reported recurrent pain were included in the "chronic recurring pain" group and those who reported continuous pain were included in the "chronic continuous pain" group. Demographic characteristics were collected using a questionnaire.

Negative affectivity was measured with the DASS-21. The DASS-21, proposed by Lovibond and Lovibond [2], has a three-factor structure (items: Depression: 3, 5, 10, 13, 16, 17, 21; Anxiety: 2, 4, 7, 9, 15, 19, 20; Stress: 1, 6, 8, 11, 12, 14, 18) and items responses in a 4-point Likert scale ranging from 0 to 3 . Also, the fit to the sample of a second order-hierarchical model (SOHM) with the "negative affectivity" factor was tested to broaden the possibilities of using the instrument to track negative affectivities as suggested by Lovibond and Lovibond [2]. Currently, there are three Portuguese versions of the DASS-21, two for Portugal $[35,36]$ and one for Brazil [37]. Thus, before using the instrument, a single Portuguese version was developed following the spelling agreement established among the Portuguese-speaking countries in 2009 so that the instrument could be more widely used. After obtaining a consensus among the authors of the study, the new version was back translated to the original English version and the equivalence between the versions was verified. A team of Psychology and Psychometrics specialists (2 Brazilians and 2 Portuguese) individually and independently evaluated and confirmed the semantic, idiomatic, cultural and conceptual equivalence of the new version with the original version. The new version was compatible with Vignola and Tucci proposal [37], with minor changes (S1 Table).

\section{c) Sample characterization}

A total of 1,167 individuals agreed to participate in the study. Of these, 1,150 answered all DASS-21 items (no pain: $n=336$, acute pain: $n=389$, chronic recurring pain: $n=247$, and chronic continuous pain: $n$ $=178$ ). It should be clarified that the 17 subjects who did not answer the scale completely only did not fill 1 item. In order to fit the models to the sample, only the fully answered instruments were used, but for the other analyzes the missing data were imputed by the regression method using SPSS 22.0 (SPSS An IBM Company, Chicago, IL).

The mean age of participants ( $n=1,167)$ was $38.6(S D=10.8)$ years. The majority of the participants were women ( $n=921,78.9 \%)$, reported working ( $n=$ 
910, 78.0\%), reported having a religion $(\mathrm{n}=990$, $84.8 \%)$, and had low economic level ( $n=736,63.1 \%$; average monthly income below $\mathrm{R} \$ 2,400.00 \sim \mathrm{USD}$ 645.00 - the values were estimated from the quotation of 02/08/2019 of the Central Bank of Brazil - US\$1.00 = $\mathrm{R} \$$ 3.72). Still, 438 individuals reported having chronic disease $(37.5 \%)$ and 324 reported having insomnia
(27.8\%). Table 1 presents characterization of the total sample and according to the groups. It is important to clarify that in order to identify the presence / absence of chronic disease and insomnia, the individuals were asked whether this condition existed or not, so that these variables were self-reported.

Table 1: Sample characterization

\begin{tabular}{lccccc}
\hline & \multicolumn{5}{c}{ Sample } \\
\cline { 2 - 6 } & Total & No pain & Acute pain & $\begin{array}{c}\text { Chronic recurring } \\
\text { pain }\end{array}$ & $\begin{array}{c}\text { Chronic continuous } \\
\text { pain }\end{array}$ \\
\hline $\mathrm{n}$ & 1,167 & 342 & 390 & 253 & 182 \\
Mean age ( $\pm \mathrm{SD})$ & $38.6 \pm 10.8$ & $38.1 \pm 10.8$ & $36.6 \pm 9.9$ & $38.1 \pm 11.1$ & $44.8 \pm 10.2$ \\
Female (\%) & 78.9 & 74.9 & 72.8 & 87.4 & 87.9 \\
Worker (\%) & 78.0 & 75.1 & 79.7 & 78.3 & 79.1 \\
Having Religion (\%) & 87.0 & 86.8 & 85.6 & 85.8 & 92.3 \\
Low economic level (\%) & 63.1 & 56.8 & 66.1 & 62.9 & 68.7 \\
Presence of Chronic & 38.8 & 31.9 & 31.2 & 44.8 & 59.8 \\
disease (\%) & 27.8 & 18.1 & 25.4 & 32.4 & 44.5 \\
Having insomnia (\%) & & & & & \\
\hline
\end{tabular}

\section{ili. Psychometric Properties Analysis}

\section{a) Construct validity}

The construct validity of DASS-21model to the data was assessed using the factorial and convergent validities $[38,39]$. The factorial validity was estimated using a confirmatory strategy (Confirmatory Factor Analysis - CFA) to verify the fit of the theoretical structure to the data. For this, both the first-order three-factor model and the second-order hierarchical model (SOHM) were tested (Fig 1). The Weighted Least Squares Mean and Variance Adjusted (WLSMV) estimation method was applied. The choice of this estimator was related to the fact that it is the most appropriate for categorical data [40]. The goodness-of-fit indices used were the ratio of chi-square to degrees of freedom $\left(x^{2} / d f\right)$, the comparative fit index (CFI), Tucker-Lewis index (TLI), and the root mean square error of approximation (RMSEA). The factor loadings of the items $(\lambda)$ were also considered. The fit of the model was considered adequate when $\lambda \geq 0.50, \chi^{2} / \mathrm{df} \leq 2.00, \mathrm{CFI}$ and $\mathrm{TLI} \geq 0.90$, and $\operatorname{RMSEA}<0.10[39,41]$.

The invariance between the samples was estimated by multigroup analysis. The CFI difference $(\Delta \mathrm{CFI})$ was used for factor loadings $(\lambda)$ and thresholds $(\mathrm{t})$. Invariance was assumed when absolute value of $\Delta C F I$ was less than 0.01 [42].

The analyses were conducted using the MPLUS software (version 7.2, Muthén \& Muthén, Los Angeles, USA).
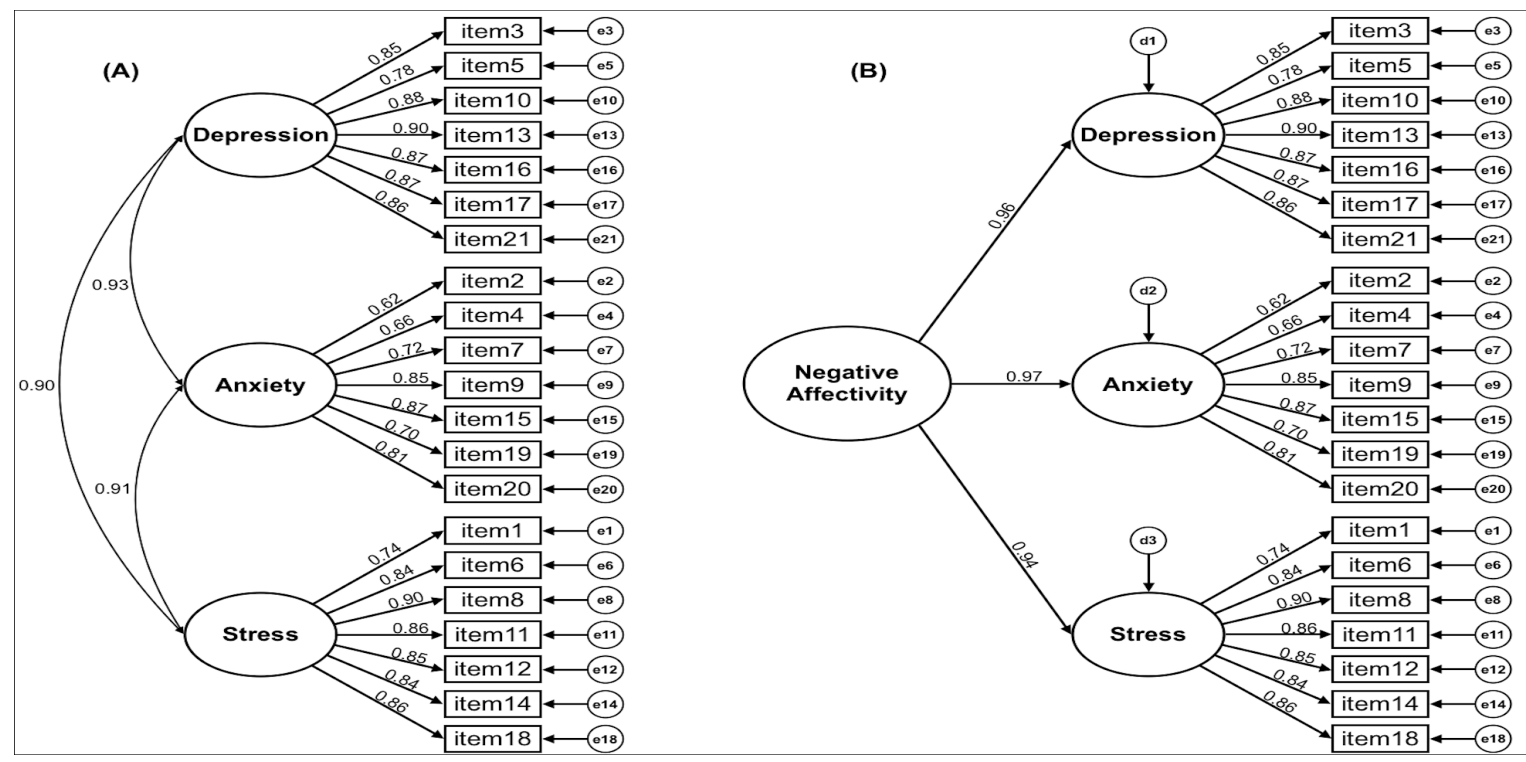

Fig 1: First-order three-factor model (A) and second-order hierarchical model (B) of the Depression, Anxiety and Stress Scale (DASS-21) and standardized estimates of the factor loadings and hypothetically causal trajectories of the models fitted to the total sample $(n=1,150)$ 
The convergent validity of each factor was estimated from the Average Variance Extracted (AVE) $[39,43]$. Value of $A V E \geq 0.50$ was considered adequate [43].

\section{Reliability}

The reliability was estimated using the composite reliability (CR) and the ordinal alpha coefficient $(\alpha)$ [39]. Values of $\mathrm{CR}$ and $\alpha \geq 0.70$ were considered adequate [39].

a) Comparison of Depression, Anxiety and Stress scores between groups

After evaluating the psychometric properties of the DASS-21 for different samples (total sample and groups), the mean scores of Depression, Anxiety and Stress were compared between the individuals with different temporal conditions of pain (no pain, acute pain, chronic recurring pain, and chronic continuous pain). The assumptions of normality (Skewness: 0.841.98, Kurtosis: 0.04-5.01; reference values: $S k<3$ e $\mathrm{Ku}<7$ [39]) and homoscedasticity were tested and the data were considered heteroscedastic (Levene's test: 3.473-11.588; $p<0.001)$ and therefore, the variances are unequal. Thus, Welch's ANOVA was used to compare the scores between the groups. Multiple comparisons were made using the Games-Howell post-hoc test. The significance level was $5 \%$. The statistical analyses were performed in the IBM SPSS Statistics 22 (IBM Corp., Armonk, N.Y., USA).

\section{b) Prevalence of Negative Affectivity}

The distribution of individuals according to the negative affectivities (Depression, Anxiety and Stress) considering the classification of severity (normal, mild, moderate, severe and extremely severe) recommended by Lovibond and Lovibond [2] was presented. The prevalence of negative affectivity was calculated per point (p) and by 95\% confidence interval (95\% Cl). The association between Depression, Anxiety and Stress and the presence/absence of pain was estimated using the chi-square test. The odds ratio (OR) was calculated to verify the chance of an individual with pain presenting
Depression, Anxiety, Stress in relation individuals without pain. Therefore, negative affectivities were dichotomized considering their presence when severity was classified as mild, moderate, severe or extremely severe (classification recommended by Lovibond and Lovibond [2]). The distribution of the individuals according to the presence of the different negative affectivity components (Depression, Anxiety and Stress) considering the number of these components present for each group was also calculated. The statistical analyses were performed in the IBM SPSS Statistics 22 (IBM Corp., Armonk, N.Y., USA).

\section{c) Predictive Model}

A multiple binary logistic regression model was elaborated to estimate the probability of occurrence of Depression, Anxiety, Stress and Negative Affectivity in the total sample excluding participants with missing data in the demographic questionnaire $(n=1,082)$ and according to the variables of interest (reference class: female, worker, having religion, high economic level, presence of chronic disease, presence of pain in the last 24 hours, having insomnia). The backward stepwise was used to elaborate the model. The statistical analyses were performed in the IBM SPSS Statistics 22 (IBM Corp., Armonk, N.Y., USA).

\section{d) Procedures and Ethical Aspects}

Individuals agreed and signed the informed consent form to participate in the study. A face-to-face interview was conducted by a single interviewer. The interviews were carried out in a reserved space in the waiting room of the participating clinics.

The study was approved by the Research Ethics Committee of the São Paulo State University (Unesp), School of Dentistry, Araraquara (CAAE Registry No.: 14986014.0000.5416).

We clarify that the design and presentation of the results of this study followed the guideline for reporting observational studies - STROBE (www.equator-network.org).

\section{Results}

\section{a) Psychometric properties analysis}

Table 2 shows the indicators of fit of the Depression, Anxiety and Stress Scale model (DASS-21) to the data of a sample of adult individuals without pain and with different temporal conditions of pain. 


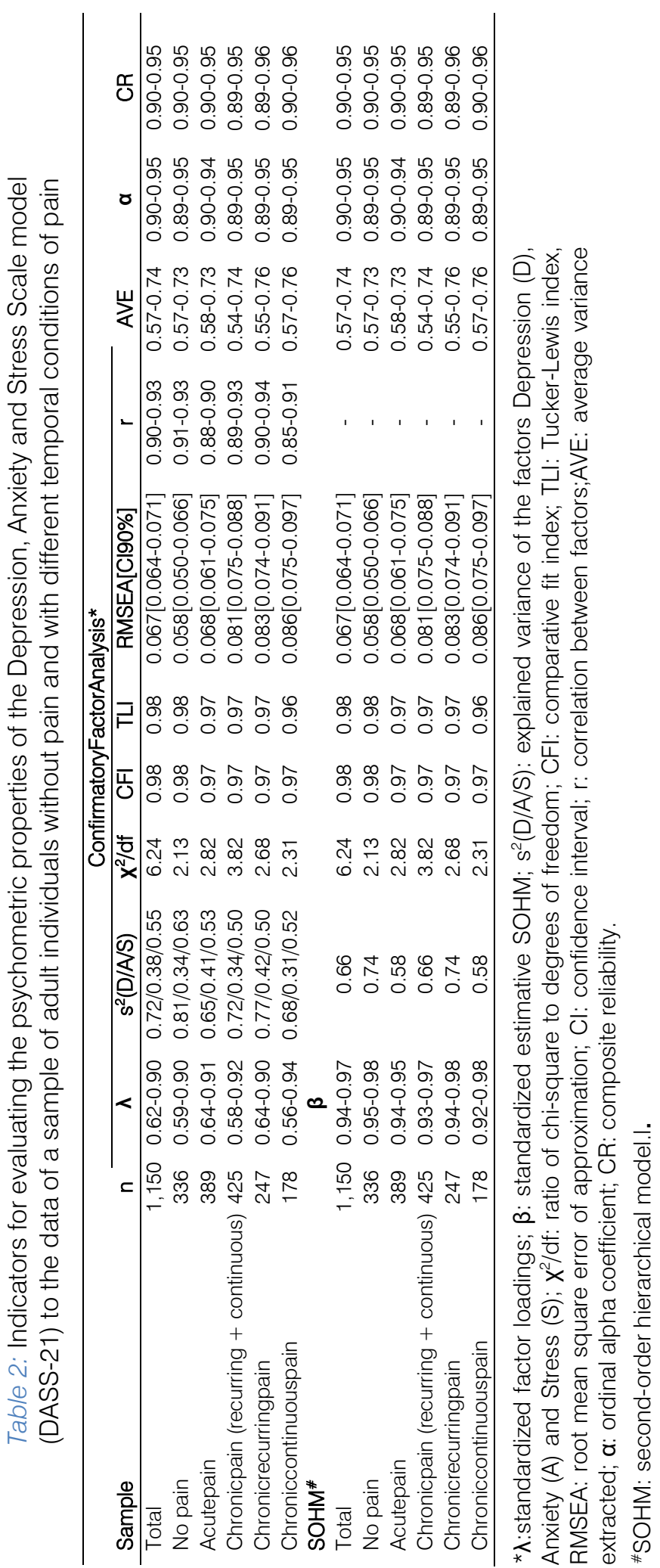

The first- and second-order models of DASS-21 presented good fit to the data pointing to adequate factorial validity in all samples. It was also observed that the convergent validity and reliability of the DASS factors were adequate. Still, a high explained variance of the Depression and Stress factors of the scale is observed.

b) Comparison of Depression, Anxiety and Stress scores between groups

Table 3 presents the comparison of the mean scores of Depression, Anxiety and Stress of the participants with different temporal conditions of pain. Higher mean scores of Depression $\quad\left(F_{\text {Welch }}=19.11\right.$; 
$p<0.001)$, Anxiety $\left(F_{\text {Welch }}=15.72 ; p<0.001\right)$ and Stress $\left(F_{\text {Welch }}=14.92 ; \quad p<0.001\right)$ were observed among individuals with pain regardless of the characteristic of the painful condition. For this reason, the individuals were reclassified into two groups ("no pain" and "with pain") to conduct the following analyzes.

Table 3: Comparison of the scores (mean \pm standard deviation) of Depression, Anxiety and Stress among adult individuals without pain and with different temporal conditions of pain.

\begin{tabular}{lcccc}
\hline \multirow{2}{*}{ Sample } & \multicolumn{3}{c}{ Mean score \pm standard deviation } & \\
\cline { 2 - 4 } & Depression* $^{*}$ & Anxiety* & Stress* $^{*}$ & $\mathrm{n}$ \\
\hline No pain & $2.89 \pm 3.71^{\mathrm{a}}$ & $2.67 \pm 3.30^{\mathrm{a}}$ & $5.13 \pm 4.49^{\mathrm{a}}$ & 342 \\
Acute pain & $4.49 \pm 5.03^{\mathrm{b}}$ & $3.83 \pm 4.36^{\mathrm{b}}$ & $6.76 \pm 5.18^{\mathrm{b}}$ & 390 \\
Chronic recurring pain & $4.98 \pm 5.32^{\mathrm{b}}$ & $4.40 \pm 4.37^{\mathrm{b}}$ & $7.52 \pm 5.43^{\mathrm{b}}$ & 253 \\
Chronic continuous pain & $5.53 \pm 5.39^{\mathrm{b}}$ & $4.74 \pm 4.68^{\mathrm{b}}$ & $7.33 \pm 5.56^{\mathrm{b}}$ & 182 \\
\hline Total & $4.29 \pm 4.90$ & $3.75 \pm 4.20$ & $6.54 \pm 5.19$ & 1,167 \\
\hline
\end{tabular}

*Welch's ANOVA ( $p<0.001)$; ${ }^{a, b}$ different letters indicate significant statistical difference (Games-Howell post hoc test; $\alpha=5 \%$ ).

c) Prevalence of negative affectivity

Table 4 shows the distribution of individuals according to the negative affectivity (Depression, Anxiety and Stress) considering the classification of severity. It is noted that the presence of pain significantly increases the chance of an individual having negative affectivities.

Table 4: Distribution of individuals [n (\%)] according to negative affectivity (Depression, Anxiety and Stress) considering the classification of severity in the samples (no pain: $n=342$, with pain: $n=825$, total sample:

$$
\mathrm{n}=1,167) \text {. }
$$

\begin{tabular}{|c|c|c|c|c|c|c|c|c|c|}
\hline \multicolumn{2}{|l|}{ Factor } & \multicolumn{5}{|c|}{ Classification - n (\%) } & \multirow[b]{2}{*}{$\mathrm{p}[\mathrm{Cl} 95 \%]$} & \multirow[b]{2}{*}{$x^{2}$} & \multirow[b]{2}{*}{ OR [Cl95\%]* } \\
\hline DASS-21 & Sample & Normal & Mild & Moderate & Severe & Extremely Severe & & & \\
\hline \multirow[t]{3}{*}{ Depression } & No pain & $322(94.2)$ & $11(3.2)$ & $8(2.3)$ & $1(0.3)$ & - & 5.85 [3.36-8.34] & & \\
\hline & With pain & $699(84.7)$ & $54(6.5)$ & $50(6.1)$ & $22(2.7)$ & - & $15.27[12.82-17.73]$ & 18.77\# & $2.90[1.78-4.74]$ \\
\hline & Total & $1,021(87.5)$ & $65(5.6)$ & $58(5.0)$ & $23(1.9)$ & - & $12.51[10.61-14.41]$ & & \\
\hline \multirow[t]{3}{*}{ Anxiety } & No pain & $315(92.1)$ & $10(2.9)$ & $14(4.1)$ & $2(0.6)$ & $1(0.3)$ & $7.89[5.03-10.76]$ & & \\
\hline & With pain & $674(81.7)$ & $53(6.4)$ & $65(7.9)$ & $24(2.9)$ & $9(1.1)$ & 18.30 [15.66-20.94] & 19.47\# & $2.61[1.70-4.02]$ \\
\hline & Total & $989(84.7)$ & $63(5.4)$ & $79(6.8)$ & $26(2.2)$ & $10(0.9)$ & $14.52[12.50-16.54]$ & & \\
\hline \multirow[t]{3}{*}{ Stress } & No pain & $324(94.7)$ & $13(3.8)$ & $5(1.5)$ & - & - & 5.26 [2.89-7.63] & & \\
\hline & With pain & 727 (88.1) & $51(6.2)$ & $47(5.7)$ & - & - & $11.88[9.67-14.09]$ & 11.09\# & $2.43[1.44-4.08]$ \\
\hline & Total & $1,051(90.1)$ & $64(5.5)$ & $52(4.5)$ & - & - & $9.86[8.15-11.57]$ & & \\
\hline
\end{tabular}

$\# \mathrm{p}<0.001$; ${ }^{*}$ calculated from the dichotomization of variables (sample $=$ no pain $\mathrm{x}$ with pain, and DASS-21 Factor: Normal $\mathrm{x}$ Affected), OR: calculated to evaluate the chance of an individual with pain to present Depression, Anxiety, Stress in relation to the individual without pain

Fig 2 shows the distribution of the participants who had at least one negative affectivity component [Depression (D), Anxiety (A) and Stress (S)] considering the number of these components present.
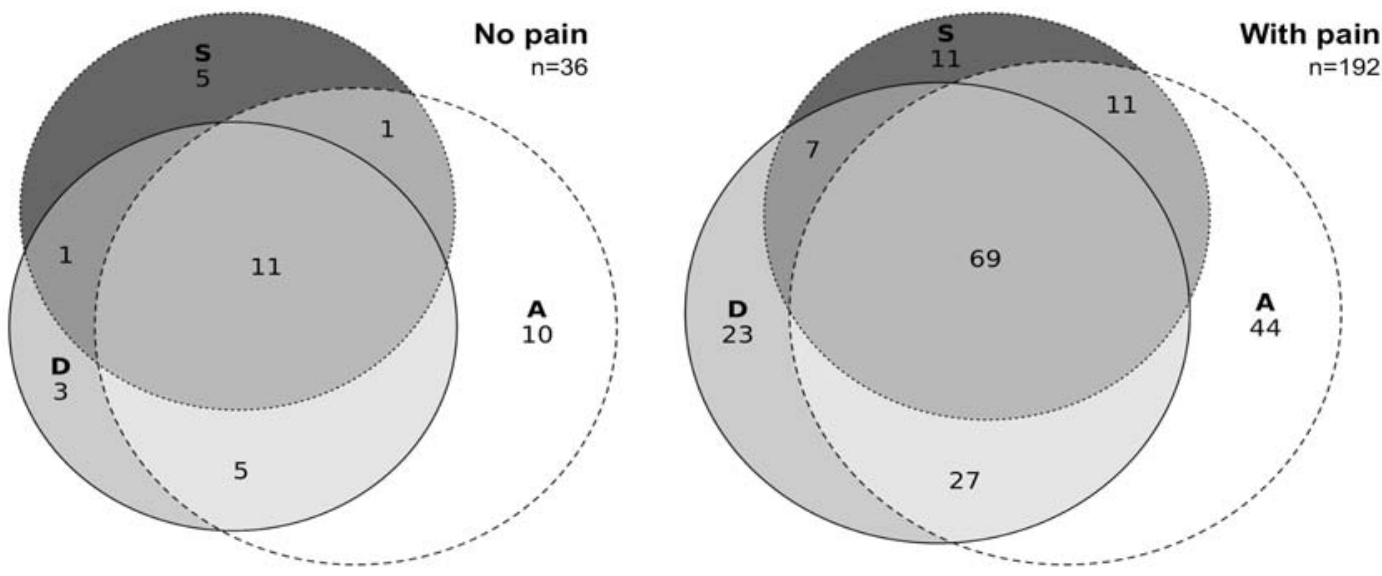

Fig. 2: Distribution of the individuals who had at least one negative affectivity component [Depression (D), Anxiety (A) and Stress (S)] considering the number of these components present in the individuals without and with pain. 


\section{d) Predictive model}

The multiple logistic regression model elaborated to estimate the probability of occurrence of Depression, Anxiety, Stress and Negative Affectivity in the total sample $(n=1,167)$ is shown in Table 5 . Having religion was a protective factor for the occurrence of
Depression and Anxiety while the presence of chronic illness, pain, insomnia and high economic level were risk factors. These were also significant risk factors for the occurrence of negative affectivity in general. Only the presence of pain and insomnia were significant risk factors for the occurrence of stress.

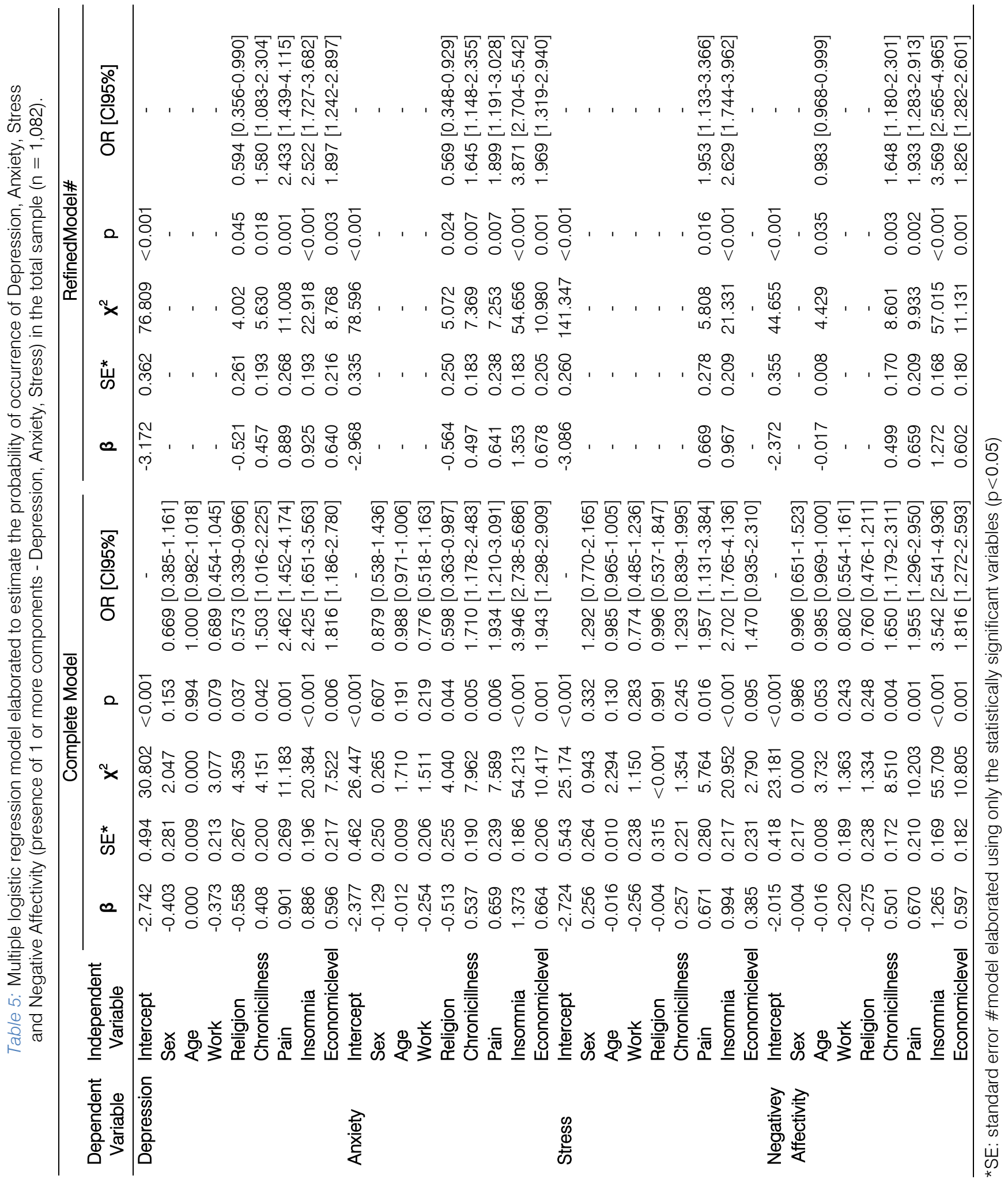




\section{Discussion}

The present study confirmed the validity and reliability of the DASS-21 model for assessing negative affectivity in adults with different temporal conditions of pain characteristics and without pain. People who reported pain had higher scores of depression, anxiety, and stress and increased likelihood of presenting negative affectivity.

Negative affectivity evaluation based on the assessment of stress, anxiety, and depression has been performed in normative [31, 35, 37, 44-46] and clinical samples of various characteristics, including in patients with chronic diseases, insomnia, and chronic pain [2, $22,47]$, which are conditions that can trigger and favor negative affectivity [7, 10-12, 48, 49]. The use of DASS allows the simultaneous assessment of stress, anxiety, and depression in both susceptible and non-susceptible populations. However, to obtain valid and reliable evaluations, the psychometric properties of the instrument should be estimated for each population to be studied, since these properties refer to the data and not to the instrument itself [39]. Thus, the present study verified the psychometric properties of the DASS in people with different temporal conditions of pain, and confirmed the validity and reliability of the data, without modifying the instrument. Sardá et al. [47] investigated and confirmed the item-scale correlations and the reliability of the DASS depression subscale in a sample of Brazilians with chronic pain. However, the authors did not present results for validity.

The lack of a significant difference between the mean scores of depression, anxiety, and stress among people with different pain types is controversial $[7,8]$. A longitudinal study [7] conducted with adults without preestablished depression and anxiety found no relationship between the pain pattern and these conditions corroborating the results of the present study. Turk and Monarch [50] support that pain is a multidimensional experience and many aspects may affect how pain is perceived and impacts a person's life. Therefore, the presence of pain alone, regardless of its pattern, might be a triggering factor for negative emotions or experiences. On the other hand, Gerrits et al [8] report that in people with diagnosed depression and anxiety disorders, pain duration might aggravate these disorders and, therefore, individuals with chronic pain can be more susceptible to depression and anxiety. Thus, negative affectivity assessment should be considered for all individuals with pain, regardless of their pattern.

Our results indicated a clear overlap of symptoms of depression, anxiety, and stress (i.e. presentation of more than one condition simultaneously) that exceeded the prevalence of each condition alone in individuals with and without pain (Fig 2). Stress, anxiety and depression are conditions difficult to discriminate completely [2], which favors their concomitant occurrence. The results are in agreement with Lovibond and Lovibond [2] who emphasize that despite the conceptual differences between these symptoms, there is a great similarity between them. Therefore, the investigation of negative affectivity, as a general concept that encompasses the mixed symptoms of these three conditions, is advised by several authors [6, 35, 36, 44]. The higher prevalence of negative affectivity among individuals with pain indicates that pain is positively correlated to stress, anxiety, and depression [51]. This result is consistent with the multidimensional theory of pain, which explains that pain has physical, social, cognitive, and affective components, and may be considered a biopsychosocial experience [50]. These components may affect how an individual perceives pain itself, which, in turn, can trigger psychophysiological processes that potentiate stressful situations, intensifying the perception of pain and increasing negative affectivity [50]. Our results indicated that the presence of pain is a relevant characteristic that should be investigated, since it may favor the development negative affectivity, which was similar to the study by Gerrits et al. [7] and Magni et al. [15].

The inverse relationship found between having religious beliefs and the occurrence of depression and anxiety has been reported also by other authors [25, 26]. Individuals with religious or spiritual beliefs and cognitions may present positive coping strategies to face the demands and challenges encountered in life [24], leading to less negative affectivity. Thus, religious beliefs can provide the individual with the perception of the meaning and purpose of life itself [25], positively influencing his mental health, especially with regard to psychological well-being [26].

In the present study, high economic level was a risk factor for both depression and anxiety as well as negative affectivity in general. Similar studies found controversial results [29, 30,52], as in the studies by Adler et al. [29] and Gallo and Matthews [52], in which symptoms of depression and anxiety were more prevalent in low-income individuals. Bayram and Bilgel [30] also found an inverse relationship between depression and stress scores assessed by DASS and family economic situation of university students in Turkey. Our results might indicate that individuals of higher economic level are more exposed to demands related to negative emotions or have less cognitive / emotional skills to deal with stressors [29] than people of lower socioeconomic level. In addition, the differences between our findings and those of other studies might be related to the different demographic and cultural characteristics of the samples.

Another relevant finding regarding increased risk of depression and anxiety was the presence of chronic disease, which is in agreement with previous studies $[10,11,53]$. Chronic diseases can be self- 
limiting, compromising actions and engagement in daily activities [10], favoring social isolation [11], and increasing the chance of developing negative affectivity. Moreover, the positive and significant association between insomnia and emotional states observed in the present study seems to be in agreement with the literature $[12,13,48,49]$. For some authors [12, 13], insomnia can both precede and follow depression and anxiety disorders. In a neurobiological perspective, insomnia can lead to changes in the regulation of neural circuits involved in the wake cycle, since cerebral regions related to affectivity and sleep can interact [48], which may influence the individual's emotional reactivity. In addition, stress is one of the psychological effects associated with insomnia [49]. Thus, individuals with difficulty initiating or maintaining sleep may be more susceptible to negative affectivity either through biological or psychological pathways, which may result in the development of mood / anxiety disorders, largely affecting mental health.

Another important outcome of this study was the creation of a regression model of factors associated with negative affectivity. Several studies indicate that individual, demographic, and clinical characteristics may help understand stress, anxiety, and depression manifestations $[7,10-13,15,21,22,24-26,29]$. The detection of negative affectivity and associated factors can provide useful information for planning individual and collective management strategies, with the primary objective of preventing mental health disorders.

The present study has limitations such as the cross sectional design, which does not allow causeeffect inference, and the non-probability sampling, which may affect the generalization of results. However, a large sample size was used to obtain more similar estimates to the values of the population. In addition, this was a screening study aimed to at identifying the occurrence probability of symptoms of mental disorders in adult individuals with different temporal conditions of pain, which we considered the major contribution of the present work. The results of this study provide information for the elaboration of strategies that favor a more integrated and decisive clinical practice, aiming at the prevention and maintenance of mental health.

\section{Vil. Conclusions}

The DASS-21 presented adequate validity and reliability for use in adults with different temporal conditions of pain and without pain. Individuals reporting pain have higher scores for the Depression, Anxiety, and Stress subscales. Individual characteristics and pain are factors related to negative affectivity that should be taken into account in clinical or research settings.

\section{References Références Referencias}

1. Denollet J. Negative Affectivity. In: Gellman MD, Turner JR, editors. Encyclopedia of Behavioral Medicine New York: Springer New York; 2013.

2. Lovibond SH, Lovibond PF. Manual for the Depression, Anxiety, Stress Scales Australia: http://www2.psy.unsw.edu.au/dass/; 1995 [updated 10/11/2014; cited 2017 13/09].

3. Association AP. Diagnostic and statistical manual of mental disorders. 5th Edition ed. Arlington, VA: American Psychiatric Publishing; 2013.

4. Association AP. Manual Diagnóstico e Estatístico de Transtornos Mentais (DSM-5). Artmed, editor2014.

5. Faro A, Pereira ME. Estresse, atribuição de causalidade e valência emocional: revisão da literatura. Arq Bras Psicol. 2012; 64(2):76-92. doi: Disponível em: http://pepsic.bvsalud.org/scielo. php?script $=$ sci_arttext\&pid =S1809-52672012 0002 $00007 \&$ lng $=$ pt.

6. Clark LA, Watson D. Tripartite model of anxiety and depression: psychometric evidence and taxonomic implication. J Abnorm Psychol. 1991;100(3):316-36. doi: http://dx.doi.org/10.1037/0021-843X.100.3.316.

7. Gerrits MMJG, Van Oppen P, Van Marwijk HWJ, Penninx BWJH, Van der Horst H. Pain and the onset of depressive and anxiety disorders. Pain. 2014; 155:53-9. doi: http://dx.doi.org/10.1016//j. pain. 2013.09.005.

8. Gerrits MMJG, Vogelzangs N, Van Oppen P, Van Marwijk HWJ, Van der Horst $\mathrm{H}$, Penninx BWJH. Impact of pain on the course of depressive and anxiety disorders. Pain. 2012; 153:429-36. doi: http://dx.doi.org/10.1016/j.pain.2011.11.001.

9. Martinez-Lavin M. Biology and therapy of fibromyalgia. Stress, the stress response system, and fibromyalgia. Arthritis Res Ther. 2007; 9(4):216. Epub 2007/07/14. doi: 10.1186/ar2146. PubMed PMID: 17626613; PubMed Central PMCID: PMCPMC2206360.

10. Askari MS, Andrade LH, Filho AC, Silveira CM, Siu E, Wang $Y$, et al. Dual burden of chronic physical diseases and anxiety/mood disorders among São Paulo Megacity Mental Health Survey Sample, Brazil. Journal of Affective Disorders. 2017; 220:1-7. doi: http://dx.doi.org/10.1016/j.jad.2017.05.027.

11. Goesling J, Clauw DJ, Hassett AL. Pain and Depression: An Integrative Review of Neurobiological and Psychological Factors. Curr Psychiatry Rep. 2013; 15:421. doi: https://doi.org/10.1007/s11920-013-0421-0.

12. Neckelmann D, Mykletun A, Dahl AA. Chronic insomnia as a risk factor for developing anxiety and depression. Sleep. 2007; 30(7):873-80.

13. Mason EC, Harvey AG. Insomnia before and after treatment for anxiety and depression. Journal of 
Affective Disorders. 2014; 168:415-21. doi: http://doi.org/10.1016/j.jad.2014.07.020.

14. Iqbal S, Gupta S, Venkatarao E. Stress, anxiety \& depression among medical undergraduate students \& their socio-demographic correlates. Indian J Med Res. 2015; 141:354-7.

15. Magni G, Caldieron C, Rigatti-Luchini S, Merskey H. Chronic musculoskeletal pain and depressive symptoms in the general population. An analysis of the 1st National Health and Nutrition Examination Survey data. Pain. 1990; 43:299-307. doi: https://doi.org/10.1016/0304-3959(90)90027-B.

16. Paéz D, Torres B, Echebarría A. Esquema de sí, Representação social y Estereotipo sexual. In: Musitu G, editor. Processos Psicossociales Básicos. Barcelona: PPU; 1990. p. 229-34.

17. Formiga NS. Diferença de gênero nos antecedentes das emoçoes de raiva, alegria e tristeza. RCE PSI. 2006; 4(6).

18. Baron R. Psychology. 3rd edition ed. México: Allyn \& Bacon; 1997.

19. Fernández I, Vergara Al. La dimensión de masculinidad-feminidad y los antecedentes, las reacciones mentales y los mecanismos de autocontrol emocional. Revista de Psicologia Social. 1998; 2(13):171-9.

20. Crawford JR, Henry JD. The Depression Anxiety Stress Scales (DASS): Normative data and latent structure in a large non-clinical sample. British Journal of Clinical Psychology. 2003; 42:111-31. doi: http://doi.org/10.1348/014466503321903544.

21. Kessler RC, Berglund PB, Demler $O$, Jin $R$, Merikangas KR, Walters EE. Lifetime Prevalence and Age-of-Onset Distributions of DSM-IV Disorders in the National Comorbidity Survey Replication. Arch Gen Psychiatry. 2005; 62:593-602. doi: http://doi.org/10.1001/archpsyc.62.6.593.

22. Wood BM, Nicholas MK, Blyth F, Asghari A, Gibson $\mathrm{S}$. The Utility of the Short Version of the Depression Anxiety Stress Scales (DASS-21) in Elderly Patients with Persistent Pain: Does Age Make a Difference? Pain Medicine. 2010; 11:1780-90. doi: http://doi.org/10.1111/j.1526-4637.2010.01005.x.

23. Nieto $M$, Romero $D$, Ros L, Zabala C, Martínez M, Ricarte $\mathrm{JJ}$, et al. Differences in coping strategies between young and older adults: the role of executive functions. The International Journal of Aging and Human Development. 2019;0(0):1-22. doi: http://dx.doi.org/10.1177/0091415018822040.

24. Ano G.G., E.B. V. Religious Coping and Psychological Adjustmentto Stress: A MetaAnalysis. Journal of Clinical Psychology. 2005; 61 (4):461-80. doi: http://doi.org/10.1002/jclp.20049.

25. Sakellari E, Psychogiou M, Georgiou A, Papanidi M, Vlachou V, Sapountzi-Krepia D. Exploring Religiosity, Self-Esteem, Stress and Depression
Among Students of a Cypriot University. Journal of Religion and Health. 2018; 57:136-45. doi: https://doi.org/10.1007/s10943-017-0410-4.

26. Khoynezhad G, Rajaei AR, Sarvarazemy A. Basic Religious Beliefs and Personality Traits. Iranian J Psychiatry. 2012; 7(2):82-6.

27. Druss BG, Rosenheck RA, Sledge WH. Health and disability costs of depressive illness in a major U.S. corporation. Am J Psychiatry. 2000;157(8):1274-8. doi: http://doi.org/10.1176/appi.ajp.157.8.1274.

28. Cavalheiro G, Tolfo SR. Trabalho e depressão: um estudo com profissionais afastados do ambiente laboral. Psico-USF. 2011; 16(2):241-9.

29. Adler NE, Boyce T, Chesney MA, Cohen S, Folkman $\mathrm{S}$, Kahn RL, et al. Socioeconomic status and health: The challenge of the gradient. American Psychologist. 1994; 49(1):15-24. doi: http://dx.doi. org/10.1037/0003-066X.49.1.15.

30. Bayram N, Bilgel N. The prevalence and sociodemographic correlations of depression, anxiety and stress among a group of university students. Soc Psychiatry Psychiatr Epidemiol. 2008; 43(8):667-72. doi: http://dx.doi.org/10.1007/s00127008-0345-x.

31. Shamsuddin K, Fadzil F, Ismail WSW, Shah SA, Omar K, Muhammad NA, et al. Correlates of depression, anxiety and stress among Malaysian university students. Asian Journal of Psychiatry. 2013; 6: 318-23. doi: http://dx.doi.org/ 10.1016/j.ajp.2013.01.014.

32. Kim $\mathrm{KH}$. The relation among fit indexes, power and sample size in structural equation modeling. Struct Equ Modeling. 2005; 12(3):368-90. doi: http://dx.doi.org/10.1207/s15328007sem1203_2

33. International Association for the Study of Pain (IASP). Pain terms: a list with definitions and notes on usage. Pain. 1979; 6: 249-52.

34. International Association for the Study of Pain IASP. Classification of chronic pain: description of chronic pain syndromes and definitions of pain terms. Seattle: IASP Press; 1994.

35. Pais-Ribeiro JL, Honrado A, Leal I. Contribuição para o estudo da adaptação portuguesa das escalas de Ansiedade, Depressão e Stress (EADS) de 21 itens de Lovibond e Lovibond. Psicologia, Saúde \& Doenças. 2004; 5(1):229-39.

36. Apóstolo JLA, Mendes AC, Azeredo ZA. Adaptação para a Língua Portuguesa da Depression, Anxiety and Stress Scale (DASS). Revista Latino-am Enfermagem. 2006; 14(6). doi: http://dx.doi.org/ 10.1590/S0104-11692006000600 006.

37. Vignola RCB, Tucci AM. Adaptation and validation of the Depression, Anxiety and Stress Scale (DASS) to Brazilian Portuguese. Journal of Affective Disorders. 2014; 155:104-9. doi: http://dx.doi.org/ 10.1016/j.jad.2013.10.031. 
38. Anastasi A, Urbina S. Psychological Testing. 7th ed. Crawfordsille, Indiana: Prentice-Hall; 1997. 721 p.

39. Marôco J. Análise de equações estruturais. $2^{\mathrm{a}}$ ed. Lisboa: ReportNumber; 2014. 389 p.

40. Muthén LK, Muthén BO. Mplus: Statistical analysis with latent variables user's guide 6.0. Los Angeles, California: Muthén \& Muthén; 2010.

41. Kline RB. Principles and practice of structural equation modeling. New York: The Guilford Press; 1998. $354 \mathrm{p}$.

42. Cheung GW, Rensvold RB. Evaluating goodness-offit indexes for testing measurement inariance. Structural Equation Modeling. 2002; 9:233-55.

43. Fornell C, Larcker DF. Evaluating Structural Equation Models with Unobservable Variables and Measurement Error. J Marketing Res. 1981; 18(1):39-50. doi: http://dx.doi.org/10.2307/ 3151312? uid $=3737664 \&$ uid $=2 \&$ uid $=4 \&$ sid $=21103$ 223270061.

44. Patias ND, Machado WL, Bandeira DR, Dell'Agio DD. Depression Anxiety and Stress Scale (DASS-21) - Short Form: Adaptação e Validação para Adolescentes Brasileiros. Psico-USF. 2016; 21(3):459-69. doi: http://dx.doi.org/10.1590/141382712016210302.

45. Sinclair SJ, Siefert CJ, Slavin-Mulford JM, Stein MB, Renna M, Blais MA. Psychometric evaluation and normative data for the Depression, Anxiety, and Stress Scales-21 (DASS-21) in a nonclinical sample of U.S. adults. Evaluation \& the Health Professions. 2012; 35(3):259-79. doi: http://doi.org/10.1177/ 0163278711424282.

46. Vasconcelos-Raposo J, Fernandes HM, Teixeira CM. Factor Structure and Reliability of the Depression, Anxiety and Stress Scales in a Large Portuguese Community Sample. Spanish Journal of Psychology. 2013; 16(10):1-10. doi: http://dx.doi. org/10.1017/sjp.2013.15.

47. Sardá Jr J, Nicholas MK, Pimenta CAM, Asghari A. Psychometric properties of the DASS-Depression scale among a Brazilian population with chronic pain. Journal of Psychosomatic Research. 2008; 64:25-31. doi: http://doi.org/10.1016/j.jpsychores. 2007.05.015.

48. Baglioni C, Battagliese G, Feige B, Spiegelhalder K, Nissen $C$, Voderholzer $U$, et al. Insomnia as a predictor of depression: A meta-analytic evaluation of longitudinal epidemiological studies. Journal of Affective Disorders. 2011; 135:10-9. doi: http://dx.doi.org/j.jad.2011.01.011.

49. Johnson EO, Roth $\mathrm{T}$, Breslau N. The association of insomnia with anxiety disorders and depression: Exploration of the direction of risk. Journal of Psychiatric Research. 2006; 40:700-8. doi: http://dx.doi.org/10.1016/j.jpsychires.2006.07.008.

50. Turk DC, Monarch ES. Biopsychosocial Perspective on Chronic Pain. In: Turk DC, Gatchel RJ, editors.
Psychological Approaches to Pain Management - A Practitioner's Handbook. 3. New York: The Guildford Press; 2018.

51. McWilliams LA, Cox BJ, Enns MW. Mood and anxiety disorders associated with chronic pain: an examination in a nationally representative sample. Pain. 2003; 106(1-2):127-33. doi: http://dx.doi.org/10.1016/S0304-3959(03)00301-4.

52. Gallo LC, Matthews KA. Understanding the Association Between Socioeconomic Status and Physical Health: Do Negative Emotions Play a Role? Psychological Bulletin. 2003; 129(1):10-51. doi: http://dx.doi.org/10.1037/0033-2909.129.1.10.

53. Miller LR, Cano A. Comorbid Chronic Pain and Depression: Who Is at risk? The Journal of Pain. 2009; 10(6):619-27. doi: http://dx.doi.org/10.1016/ j.pain.2008.12.007. 
Supporting information

S1 Table: Original and Portuguese version of the Depression, Anxiety and Stress Scale (DASS-21).

\begin{tabular}{|c|c|}
\hline Original Version* & Portuguese Version\# \\
\hline 1. I found it hard to wind down & 1. Tive dificuldade em me acalmar. \\
\hline 2. I was aware of dryness of my mouth & $\begin{array}{l}\text { 2. Estava consciente que minha boca estava } \\
\text { seca. }\end{array}$ \\
\hline $\begin{array}{l}\text { 3. I couldn't seem to experience any positive feeling at } \\
\text { all }\end{array}$ & $\begin{array}{l}\text { 3. Parecia não conseguir ter nenhum sentimento } \\
\text { positivo. }\end{array}$ \\
\hline $\begin{array}{l}\text { 4. I experienced breathing difficulty (e.g., excessively } \\
\text { rapid breathing, breathlessness in the absence of } \\
\text { physical exertion) }\end{array}$ & $\begin{array}{l}\text { 4. Senti dificuldade em respirar (ex. respiração } \\
\text { excessivamente rápida, falta de ar na ausência } \\
\text { de esforço físico). }\end{array}$ \\
\hline 5. I found it difficult to work up the initiative to do things & $\begin{array}{l}\text { 5. Tive dificuldade em tomar iniciativa para fazer } \\
\text { as coisas. }\end{array}$ \\
\hline 6. I tended to over-react to situations & $\begin{array}{l}\text { 6. Tive a tendência de reagir de forma } \\
\text { exagerada a situações. }\end{array}$ \\
\hline 7. I experienced trembling (e.g., in the hands) & 7. Senti tremores (ex. nas mãos). \\
\hline 8. I felt that I was using a lot of nervous energy & 8. Senti que estava geralmente muito nervoso. \\
\hline $\begin{array}{l}\text { 9. I was worried about situations in which I might panic } \\
\text { and make a fool of myself }\end{array}$ & $\begin{array}{l}\text { 9.Preocupei-me com situações em que eu } \\
\text { pudesse entrar em pânico e parecesse ridículo } \\
\text { (a). }\end{array}$ \\
\hline 10. I felt that I had nothing to look forward to & $\begin{array}{l}\text { 10. Senti que não tinha nada a esperar do } \\
\text { futuro. }\end{array}$ \\
\hline 11. I found myself getting agitated & 11. Senti que estava agitado. \\
\hline 12. I found it difficult to relax & 12. Tive dificuldade em relaxar. \\
\hline 13. I felt down-hearted and blue & 13. Senti-me desanimado e deprimido. \\
\hline $\begin{array}{l}\text { 14. I was intolerant of anything that kept me from getting } \\
\text { on with what I was doing }\end{array}$ & $\begin{array}{l}\text { 14. Fui intolerante com as coisas que me } \\
\text { impediam de continuar o que eu estava } \\
\text { fazendo. }\end{array}$ \\
\hline 15. I felt I was close to panic & 15. Senti que ia entrar em pânico. \\
\hline 16. I was unable to become enthusiastic about anything & 16. Não consegui me entusiasmar com nada. \\
\hline 17. I felt I wasn't worth much as a person & $\begin{array}{l}\text { 17. Senti que não tinha muito valor como } \\
\text { pessoa. }\end{array}$ \\
\hline 18. I felt that I was rather touchy & 18. Senti que estava irritado. \\
\hline $\begin{array}{l}\text { 19. I was aware of the action of my heart in the absence } \\
\text { of physical exertion (e.g., sense of heart rate increase, } \\
\text { heart missing a beat) }\end{array}$ & $\begin{array}{l}\text { 19. Eu estava consciente do } \\
\text { funcionamento/batimento do meu coração na } \\
\text { ausência de esforço físico (ex. sensação de } \\
\text { aumento da frequência cardíaca, disritmia } \\
\text { cardíaca). }\end{array}$ \\
\hline 20. I felt scared without any good reason & 20. Senti medo sem ter uma boa razão. \\
\hline 21. I felt that life was meaningless & 21. Senti que a vida não tinha sentido. \\
\hline
\end{tabular}

*Lovibond SH, Lovibond PF. Manual for the Depression, Anxiety, Stress Scales Australia: http://www2.psy.unsw.edu.au/dass/; 1995 [updated 10/11/2014; cited 2017 13/09].

\#Response categories: $0=$ did not apply to me at all (never), $1=$ applied to me to some degree, or some of the time (sometimes), 2 = applied to me to a considerable degree, or a good part of time (very often), $3=$ applied to me very much, or most of the time (almost always).

†Portuguese version was developed in the present study following the spelling agreement established among the Portuguesespeaking countries in 2009. 